Pesquisa e Reflexão em Educação Básica

\title{
Jovens narrativas gays: (a)normalidade, reconhecimento e medo nos espaços educacionais
}

Alexandre Luiz Polizel ${ }^{1}$

\begin{abstract}
Resumo:
Este manuscrito tem por objetivo traçar considerações acerca das tecnologias de poder e de resistência, evidenciadas nas narrativas de si de um jovem gay licenciando de química da Universidade Estadual de Maringá (UEM), durante sua trajetória pelos espaços educacionais. A investigação deu-se sob a perspectiva heteroautobiográfica, a fim de possibilitar a construção de narrativas de si. As construções das narrativas foram guiadas utilizando um roteiro com questões, sendo esta audiogravada, transcrita e acompanhada por tomadas de notas em caderno de campo, sendo empregada análise de discurso sob inspiração Foucaultiana. Evidenciou-se que as questões de violação atreladas a sua identidade sexual eram catalisadas pelo estatuto de verdade vigente que estabelece um quadro de normatividade cis-heteronormativa. O quadro normativo aciona tecnologias de poder sob o corpo gay que se dá: i) no âmbito do reconhecimento, em um primeiro momento negando a possibilidade de reconhecer pela não visualização de si, devido ao medo de uma violação; ii) como técnica de resistência o reconhecimento se dá em relação a um Outro membro do grupo identitário LGBT, catalisada pelas violações sofridas por estes; iii) na afirmação de si e requerimento de validação de seu modo de ser, após votação do Plano Nacional de Educação.
\end{abstract}

\section{Palavras-chave:}

Narrativas de si. Heteroautobiografia. Espaços de ensino. Normatividade. Juventudes.

\section{Young gay narratives: (a) normality, recognition and fear in educational spaces}

Abstract: This manuscript aims to outline considerations about the technologies of power and resistance, evidenced in the narratives of a young gay graduate in chemistry from the State University of Maringá (UEM), during his journey through educational spaces. The investigation took place from a heteroautobiographical perspective, in order to enable the construction of self-narratives. The construction of the narratives was guided using a script with questions, this audio being recorded, transcribed and accompanied by notes taken in a field notebook, using discourse analysis under Foucault's inspiration. It became evident that the issues of rape linked to their sexual identity were

1 Mestre em Ensino de Ciências e Educação Matemática, Professor Colaborador da Universidade Estadual de Londrina. E-mail: alexandre_polizel@hotmail.com. ORCID iD: http://orcid.org/0000-0001-6397-306X. 
catalyzed by the current status of truth that establishes a cis-heteronormative normative framework. The normative framework triggers power technologies under the gay body that occurs: i) within the scope of recognition, at first denying the possibility of recognizing by not seeing oneself, due to the fear of a violation; ii) as a resistance technique, recognition occurs in relation to another member of the LGBT identity group, catalyzed by the violations suffered by them; iii) in affirming oneself and requesting the validation of his / her way of being, after voting on the National Education Plan.

Keywords: Self-narratives. Heteroautobiography. Teaching spaces. Normativity. Youth.

\section{Narrativas jóvenes gay: (a) normalidad, reconocimiento y miedo en los espacios educativos}

Resumen: Este manuscrito tiene como objetivo esbozar consideraciones sobre las tecnologías de poder y resistencia, evidenciadas en las narrativas de un joven gay licenciado en química de la Universidad Estatal de Maringá (UEM), durante su recorrido por los espacios educativos. La investigación se desarrolló desde una perspectiva heteroautobiográfica, con el fin de posibilitar la construcción de auto-narrativas. La construcción de las narrativas se guió mediante un guión con preguntas, siendo este audio grabado, transcrito y acompañado de notas tomadas en un cuaderno de campo, utilizando el análisis del discurso bajo la inspiración de Foucault. Se hizo evidente que los problemas de violación vinculados a su identidad sexual fueron catalizados por el estado actual de la verdad que establece un marco normativo cis-heteronormativo. El marco normativo desencadena tecnologías de poder bajo el cuerpo gay se pasa: i) en el ámbito del reconocimiento, negando en un primer momento la posibilidad de reconocer al no visualizarse a sí mismo, por temor a una violación; ii) como técnica de resistencia, el reconocimiento ocurre en relación a otro integrante del grupo de identidad LGBT, catalizado por las violaciones sufridas por ellos; iii) en afirmarse y solicitar la validación de su forma de ser, previa votación del Plan Nacional de Educación.

Palabras clave: Narrativas de sí mismos. Heteroautobiografía. Espacios docentes. Normatividad. Jóvenes.

\section{Narrativas introdutórias}

Este manuscrito emerge de um estudo amplo intitulado Histórias, violências e desalojares: a trajetória de LGBTs nos espaços de ensino, realizado no ano de 2016, que teve por intuito compreender a trajetória de pessoas LGBTQIA ${ }^{1}$ pelos espaços educativos. Tal investigação verteu-se a pensar os processos de escolarização destes sujeitos, no que toca especialmente os encontros destes com as tecnologias de poder e as marcas deixadas em seu corpo e em seu modo de existir, ou seja, em sua subjetividade. Neste manuscrito, no entanto, temos por objetivo traçar considerações acerca das tecnologias de poder e de resistência evidenciadas nas narrativas de si de um jovem gay licenciando em química.

A inserção de tal trabalho ao considerar as relações entre Juventudes, Educações e Sexualidades ao considerar, juntamente a Miriam Abramovay, Mary Garcia Castro e Lorena Bernadete da Silva (2004), as juventudes enquanto período de afirmação-negociação-identificação com as dinâmicas da sexualidade, momento representado enquanto topos da reflexão de si nos encontros com os desejos e investimentos libidinais dos Outros. Esta dinâmica encontra-se atrelada com os espaços educativos considerando-os: i) espaços os quais os sujeitos encontram-se com as diferenças, divergências e diversidades de tais ambientes; ii) reflexão acerca dos processos de

1 Pessoas Lésbicas, Gays, Bissexuais, Transgêneras, Queers, Intersexuais e Assexuais. 
socialização-subjetivação e os valores privados apreendidos no núcleo familiar; iii) contato com saberes que atravessam as cientificidades-curricularidades e dizem sobre a juventude, educação e os processos de compor-sexualidades; iv) a abertura ao diálogo e ocupação temporal referente a múltiplas temáticas colocadas dialeticamente como aspectos para discutir sobre os interesses comuns e de si; v) o próprio momento, das juventudes, em que as relações sociais demandam a afirmação de si enquanto sujeito desejante.

Ainda neste sentido, vê-se em associação ao pensamento Foucaultiano (FOUCAULT, 2015) a juventude enquanto um interstício: um tempo-experiencialidade de passagem entre o ser criança e tornar-se um sujeito adulto. Neste ínterim vê-se que nesta marcação de identidade-idade dispositivos disciplinares que se investiam sobre as crianças nos espaços escolares - que confeririam sua formação enquanto sujeito-adulto - encontram resistências das juventudes de modo mais visível, são colocados em evidência pela própria contestação ou regulamentação dos corpos dos jovens: sendo representativa pensar a história da formação-subjetivação dos sujeitos nos espaços educativos, compreendo enquanto uma narrativa das juventudes-educações.

Ressalta-se, neste sentido, que os espaços educativos aqui são considerados como territórios de formação dos sujeitos, espaço de encontros entre sujeitos com diferentes modos de pensar, aprender e produzir saberes. São nos espaços educativos em que se adentra e desenvolve sua trajetória de formação, seu currículo, à medida que entra em contato na multiplicidade com processos organizativos: com saberes eleitos como formativos, ou não; que são apropriados, ou não (GOODSON, 2008; SILVA, 2006, 2015).

Tais saberes são ordenados, periodizados, trazidos discursivamente em cena nas diferentes seriações. Ordenados juntamente com a organização do espaço e do tempo, com o intuito de ampliar a produtividade. É a esta organização do espaço, tempo e saberes, que Michel Foucault (2014) tratou como os processos disciplinares da sociedade disciplinar. Os espaços educativos nascem, deste perspecto, de um arranjo da experiência formativa para ampliação da produtividade.

Tal produtividade é medida sob uma métrica, ou seja, sob um regime de verdade. Os regimes de verdade consistem em relações de saberes e poderes que delimitam o que é certo, bom, produtivo, válido, natural, normal... e seus antagônicos. São os regimes de verdade que estabelecem quadros de referências acerca dos modos de ser, estar, pensar, saber e existir. É a tal métrica que Michel Foucault $(2014,2015)$ trata como normatividade, ou seja, no delineamento da valorativa do que é normal, e com isso, daquilo que pode existir dentro de um quadro valorativo - e ao mesmo tempo de um quadro desvalorativo, à medida que se cria o desvio para dar referência antagônica ao normal (BUTLER, 2015b).

Esta perspectiva, que estabelece valores à medida que posiciona os sujeitos em um espectro de normalidade, é estabelecida discursivamente à medida que articula o funcionamento de saberes e de poderes. O poder em Michel Foucault $(2014 ; 2015)$ consiste em um sistema operatório, ou seja, ninguém detém o poder, o poder é difuso e faz-se à medida que opera, que disciplina, e que "forma(ta)" corpos em sua conformação discursiva. A forma representa a existência em relação a sua função, do funcionamento do corpo em relação a sua posição no quadro de referências.

Se o quadro de referências se funda sob a eleição e legitimação de um sistema cis-heteronormativo como norma - em compreender uma dinâmica em que é normal e natural ser um indivíduo Cisgênero ${ }^{2}$ e Heterossexual ${ }^{3}$, esperando que os sujeitos desempenhem papeis sociais para tais enquadramentos -, os desviados de tal sistema são alocados no espectro de desvio, sustentados por uma naturalização de tais posições, em operação pelos preconceitos, representações, violências e comportamentos fóbicos: por tecnologias de poder.

2 No que concerne um discurso médico-biológico, ao nascimento é designado um sexo para o recém-nascido e esperado que este performe determinados papeis de gênero correspondente aos modos de ser homem e ser mulher concebidos em um quadro de normatividade. Cisgênero consiste o sujeito que tem consonância de sua performance de gênero e o sexo designado em seu ato de nascimento.

3 A heterossexualidade consiste em um modelo normativo de orientação sexual que se pauta no binômio de gênero, homem e mulher, e opera na atração supostamente complementar deste. É o desejo direcionado entre sujeitos de gêneros opostos. 
As tecnologias de poder consistem, assim, nas estruturas que agenciam os corpos a atuarem de acordo com normas estruturadas, em relações de subjetivação-sujeição e no quadro de referências estabelecidos e legitimados (FOUCAULT, 2014, 2015). Quadro estes que colocam em efetuação também as referências discriminatórias que sustentam e propagam compulsoriamente os ordenamentos sociais normativos. É deste quadro que os LGBTs se encontram posicionados como (des) viados, como marginais, como passíveis de serem violados caso tais ações de força levem a uma readequação (ou não) destes.

Todavia, tais tecnologias que se propõem operar e reiterar o quadro de referência normativo não operam de maneira soberana ou demonstram totalidade de sua eficiência, pelo contrário, no encontro com os corpos essas tecnologias são desafiadas, negociadas, tracionadas, deslocadas e fraturadas na contestação dos regimes de saberes-poderes-verdades. A dissidência neste sentido coloca-se como contrapoder, como uma torção da norma, e é conceituada como uma tecnologia de resistência. O processo de subjetivação-sujeição dá-se exatamente neste encontro, de tecnologias de poder e de resistência, do assujeitamento ou da reivindicação (FOUCAULT, 2014, 2015; BUTLER, 2015a).

É desta óptica que Margareth Rago (2013) oferece como caminho para reconhecimento das conformações históricas, o olhar as narrativas de si. Para essa, as narrativas dos sujeitos arrastam consigo seu processo de composição, bem como mostram as marcas em seu corpo, oriundas dos encontros com as tecnologias de poder e de resistência. São as narrativas, memórias presentificadas, que à medida que são enunciadas nos trazem à cena os efeitos de tais poder, que os fazem dizíveis e permitem-nos analisá-los.

O olhar aqui guia-se então desta localidade teórica, que considera os espaços educativos como espaços que guiam condutas, à medida que formam os sujeitos mediante a disciplinarização estabelecida a partir de um quadro de referências, nos leva à reflexão que guia este manuscrito: Que tecnologias de poder e de resistência atuam em sua passagem pelos espaços educativos? Até que ponto tais medidas mostram-se técnicas disciplinares ou violações? Que tecnologia se destaca nas narrativas de um jovem gay, licenciando em química?

Demarca-se que neste manuscrito não temos o intuito de esgotar as tecnologias de poder e de resistência que atravessam os corpos gays em sua trajetória pelos espaços educativos, mas sim teorizar tecnologias que se fazem presentes nas narrativas a partir da memorização-presentificação destas.

Neste sentido, o presente manuscrito encontra-se organizado em três eixos: a) Narrando o percurso metodológico, no qual estabelecemos a composição de nosso campo metodológico locado no perspecto heteroautobiográfico; b) (A)Normalidade: acionar de um (não) reconhecimento, em que é evidenciado em um período de infância - de educação infantil ao ensino fundamental - de um não reconhecimento acionado pela tecnologia da normalidade; c) Reconhecer-se no Outro e a questão do medo, em que é observado em sua trajetória de vida no ensino médio e superior o início do reconhecimento de violências sofrido a indivíduos de seu grupo identitário e, o medo como operação desta percepção.

\section{Narrando o percurso metodológico}

Ao pensar nas narrativas podemos refletir acerca de um conjunto de frequências sonoras, de registros gráficos e escritos. A imagem que nos vem na cabeça é sempre algum tipo de linha, que se escreve em letras ou em formas gráficas. Essas sempre nos contam algo: formas, histórias, valores, acontecimentos... As narrativas são quem colocam o tônus a existência, quem as cria e as das formas (RAGO, 2013). Neste sentido, nossa preocupação é o registro das narrativas, buscando nestas alinhavarmos e vislumbrarmos as trajetórias de vida de sujeitos, os modos de constituição de suas existências, de suas vontades, de suas encruzilhadas. 
Nesse sentido, voltamo-nos a uma primeira preocupação metodológica: o trabalho narrativo, tocado em seus retalhos, requer um processo de reconhecimento, sendo para isso necessário a produção de um espaço de escuta (BUTLER, 2015a). Nesse espaço de escuta buscam-se falas de si, testemunhos, suas confissões e os silêncios; neste combinado de ecos vê-se as negociações dos processos discursivos, dos saberes e invenções de verdades acerca de si, do Outro e das contingências pelas quais passou e se constituiu.

A instauração deste espaço de escuta e dos processos de reconhecimento que neste se dão, envolve-se o encontro de corpos: daquele que narra sua vida e daquele que o escuta, registra-o e interpreta. Esse encontro é uma hibridização, visto que nos encontros dos corpos estes se hibridizam à medida que se afetam, que selecionam o que será enunciado, o que será registrado, analisado e mobilizado como currículo contados (BUTLER, 2015a; RAGO, 2013). À esta investigação interessou-se a busca destas histórias, voltando o olhar as narrativas que não se fazem evidentes nos documentos oficiais dos territórios educacionais, que se perderam em meio ao registro hegemônico, que se mantiveram como narrativas menores. E por estas serem menores ${ }^{4}$, mostram as afetações não contadas - ou melhor, não selecionadas para reiterarem o conto hegemônico das instituições.

É dessa perspectiva metodológica que partimos, aproximados do que Margareth Rago (2013) chama de heteroautobiografia. Um movimento metodológico que coloca a enunciar e registrar as narrativas, nos encontros e seleções daquilo que o contador de sua história compreende como significativo de ser narrado. Esse registro é "Hetero" ao passo que dois corpos distintos se encontram para produzir tais cacos narrativos: o biógrafo que registra a história, faz perguntas que ativam a memória e convidam a enunciar; e o enunciador que testemunha sua história, traz sua memória a cena e narra suas afetações. É biográfico à medida que um corpo narra suas vivências, (des)(re)memora-se constantemente, e faz-se contar. É autobiográfica à medida que aquele que ouve e reconhece o contador de si, cria um espaço de escuta para que o Outro se narre, faça-se em sua história. Em síntese, é heteroautobiográfica porque ambos (des)(re)memoram suas vivências, fazem-se juntos, guiam-se ao registro das análises na seletividade da memória e do enfoque do olhar: juntos constroem o mosaico narrativo da existência (RAGO, 2013).

É no processo narrativo que as experiências vividas são presentificadas, fazem-se enunciados e registros, mostram as marcas deixadas pelos encontros dos corpos com o poder, suas negociações e embates, suas técnicas de resistência, e neste jogo a instauração de seu modo de existir. Esses relatos, não se colocam como uma produção de uma história oficial, linear, Maior 5 , mas sim como um registro calcado na carne e na alma, de (re)presentificar um processo de (des) subjetivação. Nesse sentido, essa narrativa é um processo de se fazer, refazer e desfazer, de criar a si à medida que relata a si (BUTLER, 2015a; 2011; RAGO, 2013) e neste processo cíclico, do (des) subjetivar-se, nos oferece pistas das tecnologias de poder que operaram sobre este corpo, de seus modos de operação acionados nos diferentes espaços - inclusive nos espaços educativos.

Desse modo, o narrar a si cria retalhos que relatam os encontros com as tecnologias de poder e de resistências, e nesse encontro, da produção de si.

Demarca-se aqui que as tecnologias poder consistem em técnicas, ou seja, em modos de produção. Tais modos de produção reivindicam a constituição de estatutos de produção de verdade, acionando a operação de saberes e poderes, e com isso instalando mecanismos de governabilidade dos corpos - e

\footnotetext{
4 A minoridade é trazida aqui como um conceito Deleuziano e Guattariano que se resume em modos de pensamento que não se propõe como hegemônicos ou modelos a serem seguidos. Estes modos menores compreendem ao menos quatro características: a) Considerar que os aspectos constitutivos dão-se em fluxos, são fluidos e não buscam fazer-se modelos régios; b) A compreensão de que são narrativas que se dão na heterogeneidade e no devir; c) São perspectos do turbilhonar, da contingência, do acontecimento, não pretendem ser colocadas como uma relação de causa e efeito, ou de início e fim, mas sim localizadas nas singularidades; e d) Reconhece-se como problemática, em constante movimento, na afecção, na perspectiva, no desvio. Em suma pode-se compreender como saberes minoritários aqueles que se fazem coletivo, tem um propósito político e não buscam firmar-se como maior, dominante, hegemônico e régio (GALLO, 2016).

5 Como maior entende-se narrativas, saberes, ciências e poderes que se pretendem dominantes, régios, canônicos, modelos a serem seguidos, a representação do Maior é a norma (GALLO, 2016).
} 
das mentes ${ }^{6}$. Para colocar-se em vigor os estatutos de verdade maquinam regras de conduta, dispositivos curriculares e discursivos, modelos de sexualidades e seus papeis, que ao serem colocados como norma vigente, passa a atravessar os corpos e sujeitá-los: constituindo-os como sujeitos.

Todavia, os corpos não se assujeitam passivamente a tais normativas, mas negociam com estas, em seus embates, transformações, tracionamentos e quebra de mecanismos que guiam as condutas. Tal negociação dá-se na criação de formas outras de agir (em relação ao estatuto de verdade e suas normativas), da criação de contra-dispositivos, da reivindicação de modos outros de ser que escapam a normatividade vigente tratada como regimento a ser seguido. Para isso, é necessária a criação destes escapes e afirmações, o que é operado pelas chamadas tecnologias de resistências (FOUCAULT, 2015; 2014).

Ao nos inclinarmos para a escuta do Outro, ou seja, para compor os retalhos das vozes em uma heteroautobiografia, buscamos o fazer presente narrativas não convencionalmente registradas nos trajetos educacionais, em documentos oficiais e na própria historiografia dos espaços educativos. Pretendemos na vivência de um estudante universitário gay, matriculado no curso de licenciatura em química de uma Universidade Pública do Estado do Paraná, evidenciar as tecnologias de poder e de resistência que modalizaram seu corpo e sua subjetividade.

O narrador foi selecionado considerando: a) O mesmo estar matriculado em um curso de licenciatura, aspecto que confere um trânsito pela educação básica nos espaços educativos como estudante, e um retorno a estes na posição de professor; b) A participação do mesmo em grupos de estudo relacionados a temática de gênero e sexualidade, visto que este poderia ser um diferencial para o reconhecimento de tecnologias de poder, acionadas pelos estatutos de produção de verdades vigentes, que atravessam seu corpo visto sua identidade sexual; c) Sua atuação em um campo de saber das ciências exatas, o que tem sido evocado constantemente em discursos normativos-conservativos e reacionários, para justificar preconceitos nos espaços escolares - incluindo apagamentos curriculares; d) A auto-identificação deste como um garoto gay, e sua abertura para participar do projeto de pesquisa.

Após levantamento dos sujeitos que estariam alinhados a essa categoria, foi encaminhado convites por e-mail e redes sociais, sendo agendada uma entrevista pessoalmente na Universidade. Na entrevista, foi apresentado o Termo de Consentimento Livre Esclarecido 7 , que continha os preceitos éticos da pesquisa, garantia de anonimato e o roteiro com questões guias, abertas e direcionadas a nortear suas narrativas de vida - roteiro apresentado antes da entrevista a fim de garantir que questões atreladas a sua história de vida não trariam algum tipo de desconforto. Os diálogos foram audiogravados, transcritos e somados às notações do caderno de campo, especificamente para o registro das percepções e das sensações pessoais de cada participante na pesquisa (CANTANI, 2006; RAGO, 2013).

Os questionamentos guias centraram-se no entorno de sua trajetória de vida nos espaços de educação básica e superior, sua composição identitária e sua elaboração de saberes e constituição de si. Foram utilizadas as seguintes questões guias: a) Frente às violências contra as minorias sexuais de gênero, temos desde agressões físicas, psicológicas à simbólicas. Sob tais aspectos e frente a sua história de vida, o que você compreende como violência? b) Em um cenário onde a evasão da educação básica de indivíduos LGBTs tem sido recorrente em nosso país, você em sua passagem pela educação básica já sofreu violência? c) Poderia nos relatar histórias destas violências de vida e comentar se estas influenciavam no seu processo de ensino e aprendizagem e ocupação destes espaços de educação básica?

\footnotetext{
6 Compreende-se aqui o uso contínuo da palavra corpo. Demarca-se que o corpo é compreendido aqui sob uma perspectiva Foucautiana (FOUCAULT, 1996, 2014, 2015), sendo o mesmo reconhecido como uma formatação discursiva, ou seja, a própria mente, o pensamento, os campos de saberes, podem ser compreendidos como corporificações. Devido a isso, faz-se o adendo que ao falar de corpos inclui-se nesta designação as mentalidades.

7 Aprovação no Conselho de Ética e Pesquisa com Seres Humanos da UEM, n.o CAAE 55404015.5.0000.0104. Utilizamos nomes fictícios para se preservar as pessoas participantes na entrevista.
} 
d) Em um contexto de ensino superior, que você ocupa você acredita que a violência para com LGBTs tem sido ocorrente? e) Você como membro desta minoria sexual, já sofreu violência? De que forma essa ocorrência influenciou na sua relação com o lugar que você ocupa? f) No que toca a sua história de vida, frente aos apagamentos realizados no Plano Nacional de Ensino, qual sua sensação?

Considerando tais narrativas como cacos memorísticos, que foram presentificados ao serem enunciados, voltamos à análise destes por meio de análise de discurso, inspirado em uma análise de discurso de inspiração foucaultiana (FISCHER, 2001; FOUCAULT, 1996, 2014, 2015) e ancorados na perspectiva-epistemológica heteroautobiográfica (RAGO, 2013).

\section{(A)Normalidade: acionar de um (não) reconhecimento}

Ao narrar-se, é necessário posicionar quem enuncia. Trataremos neste manuscrito o narrador de si como Gleyson ${ }^{8}$, que se autoidentifica como: homem, cisgênero, branco, homossexual, classe média. De corpo obeso, afeminado e 20 anos de idade. Estudante do período noturno na Universidade Estadual de Maringá, licenciando em química. Seus relatos colocam em evidência suas marcas, voltando um olhar sobre a (a)normalidade e a percepção do que é violento. Marcas deixadas em sua trajetória, de que o violento consiste nos efeitos do fugir "[...] do que é considerado padrão, normal, uma pessoa usa isso como uma forma de te diminuir [...]".

Gleyson, ao se contar, deixou evidente que a violação que toca sua história é a deslegitimação por ser considerado anormal: "Ah, você é um gay, não vou prestar atenção direito no que você está falando, porque você não sabe o que está dizendo... você não é uma pessoa normal”. Ele é um corpo/pessoa regulado sob o que podemos chamar de tecnologia da normalização. O natural e o anormal, o enquadrado e o desviado das convenções. Junto ao seu ser estão atravessadas as discursividades produzidas sob regimes de verdade, que naturalizam coisas que não são naturais, como chacotas, desconfianças, medos, coerções.

Quando se elege a homossexualidade como uma anomalia/desvio, desconsidera-se também o seu discurso e o que dela se vivencia; trata-se esta identidade como aquela que não deve ser ouvida e considerada (FOUCAULT, 1996, 2015). Para Gleyson, não adianta que o "gay" fale, pois ou ele não será ouvido ou lhes serão captados apenas sussurros que surjam de seus lábios. Quando ouvido sua narrativa seria tratada pela marca de inferioridade, visto seu posicionamento como desviado de um sistema normativo, modo de existência de valor estabelecido como inferior, que por tal posição é/encontra-se diminuído.

Para Michel Foucault $(1996,2014,2015)$ a discursividade acionada verte-se a posicionar o sujeito em um quadro de referências normativo, o ser posicionado como desviado neste sentido é encontra-se nesta posição pelo operante de uma tecnologia de poder, operação que quanto mais sutil, mais efetiva. Todavia, vemos que na fala de Gleyson, ao ser indagado o que compreendia por uma "violação", o mesmo, cita o ser posicionado em uma localização que o "diminui", ato que é percebido, e sentido na carne e na alma. Para Judith Butler (2011, 2015a, 2015b), a posição de inferioridade é também o posicionamento destes corpos como algo que não importa, como vidas matáveis, ou seja, como corpos aos quais a violação passa a ser autorizada.

A naturalização de certas condutas e pensamentos foi uma tônica nas narrativas deste. Em suas permanências pelas instâncias de ensino, ele expôs as marcas de suas vivências na sociedade normativa. Ele ponderou. $\mathrm{Na}$ conversa, iniciou sua fala pensando na sua infância, em quando era criança e não estava "sintonizado com o que a sociedade acha certo", em quando a família lhe

8 Neste caminho, marcamos a história de vida atravessada pela identidade de Gleyson Batista, jovem homossexual assassinado a facadas no município de Ouro Preto do Oeste (RO). O uso de tal nomenclatura foi combinado com o sujeito de pesquisa, com o intuito de realizar uma homenagem a aqueles que tiveram sua trajetória de vida interrompida nos encontros com as tecnologias de poder (BERNARDI, 2016). 
empunha pressões ou quando ele elogiava seu colega ao dizer "Ah, tal menino é bonito". Lembrou de um festejo familiar, quando um de seus parentes ouviu-o dizer que o menino era bonito e exclamou: "Pô, isso não é normal, vamos bater nele". Desta experiência podemos inferir que a primeira instância educacional violenta foi a própria família, embora ela também misture o que se entende por afeto com o que se conforma em efeitos negativos, num misto de acolhida e repulsa quando se tem uma identidade diferenciada da normalidade eleita. A família também é a primeira instância a naturalizar certos padrões que ficam entranhados nas pessoas e é preciso muito diálogo e desconstrução para se separar deles.

Dessa forma, a organização do espaço familiar é realizada discursivamente, instaurando um dispositivo da sexualidade: da vigília, identificação de possível desvio, busca de correção por vias de violações caso necessário. A tentativa da família é a de readequação do sujeito a norma, via violação e supressão de seus caracteres performativos de desvio (FOUCAULT, 2015). O próprio agenciamento do medo de ser violentado, ou de ser despejado é trazido como uma violação simbólica que busca a manutenção do quadro de referências normativo.

Em seu relato, Gleyson assinalou sua passagem pelo ensino fundamental. Todo seu trajeto deu-se em uma escola privada, com certa seguridade e blindado com algumas condições sociais precárias. Narrou que "[...] sofria mais violência por parte dos colegas de sala, 'chamação' de nomes, enfim [...]", e que "não estava bem consigo mesmo para chegar nas pessoas e se abrir e dizer 'olha eu gosto de meninos". A escola é a segunda instância de reiteração das violências sociais. Nas falas, dois violares que nos tocam ficam evidentes: a) o não se reconhecer; $\mathrm{e}, \mathrm{o}$ b) não pode se dizer homossexual.

É evidente que a tecnologia da normalidade, e a eleição do modo de vida homossexual como anormal, carreou durante sua infância dois violares de atravessamento que frequentemente são trazidos na narrativa: a constante ameaça de violência e, os xingamentos. A operação aqui é de uma violência psicológica, que opera na saúde mental do sujeito, e também simbólica (BOURDIEU, 1999). Ambas acionadas pelo quadro de referência que estipula a dicotomia de normalidade-anormalidade. A possível manifestação de uma homossexualidade era suprimida, pelo medo da promessa de violência; ou da violência diretiva por meio de xingamentos, que levanta a "desconfiança da manifestação". A tecnologia da normalidade assim pode ser compreendida de duas formas: a) de uma perspectiva, pautada na produtividade de um regime das visibilidades, dos saberes e modos de ser e estar baseados na óptica, no ver como modo de reconhecer. Ele não se via em tal posição pois não se reconhecia enquanto tal; b) outra leitura possível é um olhar ao não poder se dizer enquanto homossexual, o dizer configura um ato de confissão, da produção de uma verdade sobre si $^{9}$, e deste modo o sistema normativo aciona sistemas de interdição que o impossibilitariam de tal (FOUCAULT, 2014, 2015), dentre eles o não reconhecimento em seu próprio enunciar-se. Nesse sentido, o não se ver e o não poder se dizer enquanto tal, dado sua posição no quadro da (a)normalidade, via acionamento de tecnologias de poder e violações, como o ato coercitivo.

A coerção é uma tecnologia de poder que atua controlando os indivíduos e a ameaça é a coibição de suas expressões. Ao se ameaçar e se coibir, proíbe-se o dizer-se e se legitimam as violências que operam pelo poder e interferem nos projetos de vida das pessoas. Essas práticas são tão entranhadas socialmente que, ao ser indagado quanto à possível influência das violações em seu processo de ensino e aprendizagem, Gleyson descarta a existência delas nos atos educativos e explicou que: "No processo de ensino e aprendizagem não, talvez no processo de interação com os colegas de classe, já que as violências não eram uma coisa tão livre, era uma coisa mais comedida. Eu tinha que me comportar".

Percebemos que Gleyson seccionou a violência e não a vê como um processo formativo do currículo oficial, colocando-a ao nível dos atos de seus colegas, ao nível das brincadeiras e não

9 Sob tal perspecto o não poder se dizer, reconhecer e enunciar tal verdade sobre si, é acionado também como mecanismos a impossibilidade de denunciar e registrar as violações sofridas. 
como algo intrínseco às dinâmicas escolares. Entretanto, os saberes veiculados na socialização com colegas e com a comunidade escolar também se encontram relacionados com os processos de aprendizagem e de conformação identitária. Os saberes culturais que atravessam a escola e se hibridizam em seus currículos negociáveis também são saberes formativos (GOODSON, 2008; SILVA, 2006, 2015). Os efeitos de tecnologias de poder e violações dos currículos passam a operar de forma não perceptível, o que Michel Foucault $(1996,2014,2015)$ trataria como uma operação sutil e efetiva do poder, e Pierre Bourdieu (1999) trataria como um poder e violência simbólico/a.

\section{Reconhecer-se no outro e a questão do medo}

$\mathrm{Na}$ trajetória da escolarização, Gleyson falou dos fatos que representam seu ensino médio, período que ele aponta como espaço de aceitação e de certa blindagem. Vê-se aqui o acionamento de uma tecnologia de resistência, se antes não era permitido que o mesmo se vesse enquanto homossexual ou reconhecido como tal, este traciona tal normativa e reivindica seu reconhecimento (BUTLER, 2015a).

Apesar de declarar não sofrer diretamente violências, ou não as reconhecer (BOURDIEU, 1999) nesse momento de sua vida, ele destaca que no colégio que transitou pediram a outro aluno homossexual para "ser menos bicha". Este revirar memorístico é um traço de que tal história deixou marcas na produção identitária deste contador de si e ele a recria ao trazer suas experiências passadas. $\mathrm{O}$ apagamento que feriu o colega também o feriu, ainda que indiretamente, atuando na regulação de seu corpo e reverberando, em muitas falas, que são híbridas de reconhecimento de estratégias de bullying como violências e da não consideração dessas. Existe neste sentido um interstício, ele não reconhece as violações lançadas sobre seu corpo em si, ele as reconhece no espelho do olhar ao Outro (BUTLER, 2011, 2015a, 2015b).

Ao dizer de períodos posteriores, durante sua passagem no curso superior, ele demarcou que os professores "mais antigos" se mostravam mais resistentes à presença de LGBTs na instituição, mas não caracteriza isso diretamente como homofobia, um efeito da tecnologia da normatização deixar as linhas de forças que incidem sutis, naturalizadas, simbólicas (BOURDIEU, 1999; FOUCAULT, 2014, 2015). Demarcou que as violências no meio universitário ficam restritas aos comentários “[...] carregados de ódio em páginas do Facebook". Estas visões de violências veiculadas em maior parte nas redes virtuais estão atreladas à ideia de impunibilidade. Por terem se naturalizado, são tidas como "sarros" e piadas, apesar de se converterem em tecnologias de poder sobre os outros. Nos espaços de pedagogias culturais, quem são os corpos eleitos para serem punidos ou não? Mesmo com a tramitação de legislação específica para a regulamentação dos espaços digitais, ainda se encontram a curtos passos as políticas antiviolências aplicadas a esses e algumas pessoas acabam por promover uma visão de superioridade em detrimento a outros pontos de vista nos espaços virtuais (SILVEIRA, 2010).

Ao lidar com sujeitos que reconhecem, enunciam e defendem a si, as violações para com os desviados da tecnologia da normalidade não cessam, mas buscam localidades que podem fazer-se sem sanções legais ou enfrentamentos diretos, como o ciberespaço (SILVEIRA, 2010). Em tal sentido, vê-se também, que Gleyson reconhece que o próprio espaço do ensino superior vaza, ele não é mais restrito apenas ao espaço físico da instituição, mas se encontra digitalizado nas redes sociais. Pessoas que muitas vezes nem fazem parte de tal espaço físico, mas destilam violências no espaço virtual.

Os comentários fóbicos não foram diretamente endereçados à pessoa Gleyson, mas, sim, ao grupo identitário ao qual pertence (LGBTs). Ele reforçou que as entonações se focaram em críticas a casais homossexuais que demonstraram afeto no campus e no fato de duas travestis terem concluído graduações na Universidade Estadual de Maringá. Ele apontou que muitos colegas veem isso como 
algo "nada especial" e que se devem criticar os estudos de gênero nos espaços universitários. Ele percebeu que tais violações influenciaram na ocupação de espaços acadêmicos, seja por resistência ou pelo medo de "[...] não se sentir seguro". Na coletividade há uma espécie de blindagem, mas, também, de não pertencimento pois Gleyson parece dissociar este componente ao não se colocar ou se sentir dentro do grupo LGBTs atingido pelos comentários.

Neste sentido, vê-se que a principal operação e tração entre as tecnologias de poder e de resistência acionadas pela normatividade, dão-se nas narrativas de Gleyson, por meio dos modos de reconhecimento. As tecnologias de força operam instaurando um não se reconhecer e enunciar-se como pertencente de uma sexualidade desviada, no caso de Gleyson de seu corpo gay/homossexual; em contraponto são ativadas tecnologias de resistências no encontro com o Outro, em que os impedimentos de se ver pelas ameaças de violações físicas e mentais, passam a se esfacelar à medida que o mesmo se depara com outros indivíduos LGBTs sendo violentados física, verbal ou simbolicamente. É na própria subalternidade e violações criadas pelas tecnologias de poder das normatividades que a resistência se faz evidente e abre fraturas para o reconhecimento (BUTLER, 2011). A violência que impede o reconhecer é a mesma que produz o reconhecimento.

Na sequência discursiva da fala deste, a tecnologia de poder que atua na Universidade, ainda que veladamente para alguns, é a tecnologia do medo que funciona juntamente a ameaças virtuais, sutis e muitas vezes não faladas. $\mathrm{O}$ medo se soma à ideia de não ser bem-vindo no local, de ser atingido a qualquer momento e há uma série de outras violências que Gleyson viveu e que, por isso mesmo, não quer ser mais vítima. É a ameaça do castigo, reverberada da infância aos dias de universitário, que o desloca dos lugares e da possibilidade de se relatar diretamente como um sujeito que sofre essas mesmas violências. Embora a tecnologia esteja influenciando suas expressões, caberia a ele adentrar nas negociações e resistir ou ressignificar os espaços que ocupa e a sua própria identidade (BUTLER, 2015a; FERRARI, 2006).

No Facebook e por meio de um núcleo de estudos e pesquisas em diversidade sexual que Gleyson teve contato com a discussão de planos de educação que falavam sobre gênero. Ele enredou esse episódio como um cenário que retirou os termos ligados à sexualidade e gênero das metas educacionais e, ao olhar para isso, percebeu um apagamento de sua orientação de desejo, afirmando que sua "[...] forma de amor também é válida". É o momento de afirmação de si, que faz conclamar sua forma de amar como válida. Os Planos de Educações fazem o trazer em sua narrativa os ideais de afirmação e de validade de seu modo de ser, em contraponto a visão de inferioridade que lhe era conferida pela sua identidade homossexual. Neste sentido, como artefato relacionado as trajetórias educacionais e dado suas intensidades de reconhecimento a partir do Outro, dão evidência de que este consiste em um gatilho que reivindica a afirmação de seu modo de existência para garantia de que outros jovens LGBTs não passem pelas mesmas violações que seu corpo enfrentou - mesmo sem perceber, visto o potencial da violência simbólica (BOURDIEU, 1999).

Se sua narrativa de inferiorização e não reconhecimento, de sua primeira violação, se inicia no interior da família, é a ela que o seu ato afirmativo retoma. Gleyson destaca que foi para o interior de suas relações familiares que este currículo em processo de construção transbordou. Apresentou que em uma festa, quando os integrantes estavam bêbados, que foi possível ver "[...] saindo da boca de minha tia, dos meus primos [...] que sabem que eu sou gay e repetem essa barbaridade na minha frente, é uma coisa muito entristecedora, deprimente [...]", a violência do processo de construção escorre para outros espaços e relações. Ao tentar argumentar, colocar seu ponto de vista ele evidenciou que o "ódio blindava tanto que eles não queriam ouvir, apenas tratar aquilo como uma 'sem vergonhice' que não poderia ser ensinada às crianças”. Gleyson entoou que este processo o levou a criar outros espaços "não amigáveis" para a população LGBTs. "Para estar aqui, para continuar ocupando estes lugares, é preciso de muita força”.

O dispositivo da (i)moralidade que carregamos desde a mais tenra infância se converte em uma tecnologia atravessa os currículos e delineia quais serão as abordagens de sexualidade nesses; 
parece, ao nível do senso comum, pelo menos, que o mal se encontra ancorado nas questões de gênero, que buscam a perversão do outro e uma perturbação da norma (BRITZMAN, 2015).

Assim, o posicionamento de Gleyson, torna-se o não se posicionar. O silêncio faz-se a resistência daquele que se reconheceu (BUTLER, 2015a).

\section{Considerações finais}

Neste manuscrito buscou-se os usos das narrativas de si, guiadas por um perspecto heteroautobiográfico como modo de compreender o trânsito de um jovem licenciando, gay, pelos espaços educacionais. Vê-se que estas narrativas carregam em si marcas deixadas em seu corpo, nos encontros deste com as tecnologias de poder, e em sua devolutiva por meio de tecnologias de resistência.

Evidenciou-se que nas narrativas de Gleyson, a tecnologia de poder trazida à cena e que atravessa seu corpo, são acionadas pela normatividade vigente, no que toca principalmente o posicionar seu corpo como desviado e anormal. Este posicionamento aciona linhas de força que não permitem o reconhecimento e a enunciação de si como sujeito homossexual, em seu período de infância - demarcando a guia temporal da educação infantil e fundamental. Este é um espaço de interdição dos processos de reconhecimento de si, do ver e enunciar-se, ou seja, da criação da imagem de si e da verdade de si via técnicas enunciativas que marcam um testemunho de verdade. A interdição aqui é operada por ameaças de violência física e por constantes violências verbais que colocam em dúvida sua identidade sexual.

Vê-se em um segundo momento que durante o ensino médio e superior Gleyson começa a reconhecer, sendo tal reconhecimento guiado pela dinâmica do espelho, de modo que o mesmo não se reconhece vítima de violações e tecnologias de poder, mas reconhece outros LGBTs como indivíduos violados pela sua característica de identificação sexual. É o se ver no outro que aciona a tecnologia de resistência do reconhecer-se, do se sentir afetado pelas violências fóbicas fundadas no quadro de referência das (a)normalidades. Neste momento, o medo de ser vítima deste tipo de violação é narrado, o que apresenta o aspecto dual da violência: é na violência que se reconhece no outro, mas também é devido a violência que não se reconhece.

Em um terceiro movimento, vê-se que as votações dos Planos de Educações mostraram-se um acontecimento significativo na trajetória formativa deste sujeito. É quando se toca nesta temática que se faz enunciar uma afirmação de si e um requerimento de validade em sua "forma de amar" e embates com familiares que (não) o "(re)conhecem". Tal momento afirmativo oferece como evidência uma inquietação, a supressão das discussões de gêneros e sexualidades para supressão das desigualdades como meta educativa o faz se ver. Assim, ao considerar seu reconhecimento a partir do Outro, é consonante que sua inquietação e afirmação de si dá-se como uma preocupação para com outros jovens homossexuais que passarão pelos espaços educacionais. Não se enuncia uma violação direta aqui, mas dá indícios de sua preocupação com as violações que ainda não são nomináveis - pelo seu caráter simbólico e naturalizado.

É neste ato afirmativo que Gleyson aciona outra tecnologia de resistência - em resposta a tecnologia de poder que o retira como meta o direito da educação para a supressão das desigualdades - o direito de não se posicionar, e utilizar de seu silêncio como espaço de resistência.

Pontuamos aqui, que o intuito deste manuscrito não é fechar, mas abrir e convidar para o emergir de narrativas outras, que evidenciem outras tecnologias de poder e resistência que incidem sobre corpos dissidentes da normatividade vigente. 


\section{Referências}

ABRAMOVAY, Miriam; CASTRO, Maria Garcia; SILVA, Lorena Bernadete da. Juventudes e Sexualidades. Brasília, DF: Editora Unesco Brasil, 2004.

BERNARDI, Marco. Mister Rondônia é indiciado por matar gerente de banco após relação sexual. G1, Ji-Paraná, 7 dez. 2016. Disponível em: http://g1.globo.com/ro/ji-parana-regiao-central/noticia/2016/12/mister-rondonia-e-indiciado-por-matar-gerente-de-banco-apos-relacao-sexual.html. Acesso em: 13 de jan. 2021.

BRITZMAN, Deborah. Curiosidade, sexualidade e currículo. In: LOURO, Guacira Lopes (org.). O corpo educado: pedagogias da sexualidade. 3 ed. Belo Horizonte: Autêntica, 2015. p. 83-112.

BOURDIEU, Pierre. A dominação masculina. Rio de Janeiro: Bertrand Brasil, 1999.

BUTLER, Judith. Relatar a si mesmo: crítica à violência ética. Belo Horizonte: Autêntica Editora, 2015a.

BUTLER, Judith. Quadros de guerra: quando a vida é passível de luto? Rio de Janeiro: Civilização Brasileira, 2015 b.

BUTLER, Judith. Vida precária. Contemporânea, São Carlos, v. 1, n. 1, p. 13-33, jan./jun. 2011.

FERRARI, Anderson. A “bicha banheirão" e o "homossexual militante”: grupos gays, educação e construção do sujeito homossexual. In: REUNIÃO ANUAL DA ANPED - EDUCAÇÃO, CULTURA E CONHECIMENTO NA CONTEMPORANEIDADE, 29., 2006, Caxambu. Anais [...]. Caxambu: ANPEd, 2006. p. 1-16.

FISCHER, Rosa Maria Bueno. Foucault e a análise de discurso em educação. Cadernos de Pesquisa, São Paulo, n. 114, p. 197-223, jul. 2001.

FOUCAULT, Michel. A ordem do discurso. São Paulo: Edições Loyola, 1996.

FOUCAULT, Michel. História da sexualidade I: a vontade de saber. 3 ed. São Paulo: Paz e Terra, 2015.

FOUCAULT, Michel. Vigiar e punir: nascimento da prisão. 42 ed. Petrópolis: Vozes, 2014.

GALLO, Silvio. Em torno de uma educação menor: variáveis e variações. In: BRITO, Maria dos Remédios de; GALLO, Silvio (org.). Filosofias da diferença e educação. São Paulo: Editora Livraria da Física, 2016. p. 15-46.

GOODSON, Ivor Frederick. Currículo: teoria e história. 8. ed. Petrópolis: Vozes, 2008.

RAGO, Margareth. A aventura de contar-se: Feminismos, escrita de si e invenções da subjetividade. Campinas: Editora Unicamp, 2013.

SILVA, Tomaz Tadeu da. Documentos de Identidade: uma introdução às teorias do currículo. Belo Horizonte: Autêntica, 2015.

SILVA, Tomaz Tadeu da. O currículo como fetiche: a poética e a política do texto curricular. Belo Horizonte: Autêntica, 2006.

SILVEIRA, Sergio Amadeu da. Ambivalências, liberdade e controle dos ciberviventes. In: SILVEIRA, Sergio Amadeu da (org.). Cidadania e redes digitais. São Paulo: Comitê Gestor da Internet no Brasil: Maracá, 2010. p. 63-86.

Data de submissão: 13/01/2021

Data de aceite: $25 / 01 / 2021$ 